\title{
Research on optimal configuration strategy of energy storage capacity in grid- connected microgrid
}

\author{
Jianlin Li ${ }^{1}$, Yushi Xue ${ }^{1 *}$, Liting Tian ${ }^{1}$ and Xiaodong Yuan ${ }^{2}$
}

\begin{abstract}
The optimal configuration of battery energy storage system is key to the designing of a microgrid. In this paper, a optimal configuration method of energy storage in grid-connected microgrid is proposed. Firstly, the two-layer decision model to allocate the capacity of storage is established. The decision variables in outer programming model are the capacity and power of the storage system. The objective is the least investment on the battery energy storage system. The decision variable in inner programming model is the charging and discharging power of battery. The objective is the lowest power fluctuation on the connection line. Then a case containing a grid-connected microgrid with wind power, photovoltaic, battery energy storage and load is studied, and the multi-scenario probabilistic method is used. The last result of energy storage configuration is calculated through the probability of each scene.
\end{abstract}

Keywords: Energy storage, Optimal configuration, Dynamic programming, Two-layer decision, Scene analysis

\section{Introduction}

Renewable energy is volatile and intermittent, therefore to stabilize its energy consumption through the energy storage technology is necessary. The battery energy storage technology is becoming one of the promising development direction with those advantages such as high energy density, flexible installation and high charging and discharging speed [1-3]. The Microgrid technology is an important form of efficient use of distributed renewable energy, and the optimal allocation of energy storage capacity is an important problem in the design of grid-connected microgrid.

There are many related research results about the allocation strategy for storage capacity in micro-grids. In the literature [4-6], the distribution of the fluctuation of the microgrid is summarized by analyzing the historical operational data, and then the capacity of the energy storage system is obtained based on the

\footnotetext{
* Correspondence: suiningxys1@163.com

${ }^{1}$ State Key Laboratory of Operation and Control of Renewable Energy\&Storage Systems, China Electric Power Research Institute, Beijing 100192, China

Full list of author information is available at the end of the article
}

stabilization effect and cost. In $[7,8]$, the time constant of the best first-order low-pass filter is determined by the stabilizing effect of the grid-connected output power, and the power and capacity of energy storage system are configured by the time constant. Literature $[9,10]$ uses the spectrum analysis method to optimize the output power storage, but this method is only a single-objective optimization to stabilize photovoltaic fluctuations without considering the cost factor. In $[11,12]$, the operation characteristics of important load in industry, and the optimization method of energy storage capacity of industrial photovoltaic microgrid is constructed with the aim of maximizing the utilization ratio of $\mathrm{PV}$ and the maximum annual net profit, but the impact of new energy volatility to grid is not involved. In [13, 14], a method of rationally configuring the composite storage capacity is proposed for the microgrid including photovoltaic power generation, wind power generation and typical load. A multi-objective optimization model with the lowest equipment cost, the best power matching and the most smooth renewable energy output power is established and the solution method is an adaptive inertia weight particle swarm optimization algorithm. In 
view of the randomness of new energy output, literature [15-17] puts forward a hybrid energy storage capacity allocation method based on opportunistic constraint planning, and the genetic algorithm is used to solve the problem with the lowest cost, but the optimization for energy storage to stabilize power fluctuations is not taken into account.

In this paper, the optimal allocation strategy of energy storage capacity in the grid-connected microgrid is studied, and the two-layer decision model is established. The decision variables of the outer programming model are the power and capacity of the energy storage. The objective is the least investment of the energy storage and the fluctuation. The decision variable of the inner-layer programming model is the charging and discharging power of the energy storage at the operation stage, the objective is the lowest power fluctuation of the system connection line. Then a case study of a grid-connected microgrid with wind power, photovoltaic, battery energy storage and load is given. Through the case study, the multi-scenario probability method is used to make the decision of the energy storage configuration.

\section{The two-layer decision problem}

The two-layer decision problem is an optimization problem with two-level hierarchical structure, and the outer the inner layer optimization problems have their own objective function and constraints. The objective function and constraints of the outer optimization problem are not only related to the decision variables of the outer optimization problem, but also on the optimal solution of the inner optimization problem. The optimal solution of the inner optimization problem is also affected by the decision variables of the outer optimization problem. The general mathematical model of the two-layer decision problem is as follows:

$$
\begin{aligned}
& \left\{\begin{array}{l}
\min _{x} F(x, y) \\
\text { s.t.g } g(x, y) \leq 0
\end{array}\right. \\
& \left\{\begin{array}{c}
\min _{y} f(x, y) \\
\text { s.t. } h(x, y) \leq 0
\end{array}\right.
\end{aligned}
$$

In the above formulas: $x \in R^{n_{x}}, y \in R^{n_{y}}$ are the decision variables of the outer optimization problem and the inner layer optimization problem, respectively. $F, f: R^{n_{x}+n_{y}} \rightarrow R$ are the objective functions of the outer optimization problem and the inner layer optimization problem. $g$ $: R^{n_{x}+n_{y}} \rightarrow R^{n_{l}}$ are rrespectively the Restrictions of the outer optimization problem and the inner layer optimization problem.
It is usually difficult to obtain the global optimal solution of the two-layer optimization problem, and it is considered that the optimal solution is obtained by the iterative approximation of the numerical solution and satisfying certain convergence conditions.

\section{Energy storage configuration model}

In the two-layer programming model proposed in this paper, the decision variables of the upper-level model are the capacity and power of the storage system and the objective is the lowest cost of the battery energy storage system. The decision variables in the lower-level model is the charging and discharging power of battery. With the increasing number of grid-connected microgrids, the power fluctuations on connection line will adversely affect the stability of the grid. So in the lower-level model, the objective is the lowest power fluctuation of the system connection line.

\subsection{The upper-level model}

The objective function is:

$$
\begin{aligned}
\min C_{A}= & c_{1} P_{E S}+c_{2} E_{E S}+ \\
& \lambda \sqrt{\frac{1}{N-1} \sum_{i=1}^{N}\left(P_{E S}(i)+P_{L}(i)-P_{G}(i)-P_{\text {base }}\right)}
\end{aligned}
$$

In the above formula, $c_{1}$ is the unit power cost, for lithium batteries, lead acid and other battery energy storage, it is mainly the cost of power converter system (PCS); $c_{2}$ is the unit capacity costs, it is mainly the cost of the battery; $\lambda$ is the penalty factor for the power fluctuation of the connection line; $P_{E S}$ is the power of energy storage in microgrid; $P_{L}$ is the power of load in microgrid; $P_{G}$ is the power of generation in microgrid; $P_{\text {base }}$ is the demand capacity reported to the grid by the microgrid corporation.

The constraints are shown as follows:

$$
\begin{array}{ll}
P_{E S} \leq P_{M} & E_{E S} \geq \frac{1}{S O C_{M}-S O C_{0}} \sum_{k=1}^{i} P_{E S}(i) \Delta t \\
E_{E S} \leq E_{M} & P_{E S} \geq P_{E S}(i) \\
i=1,2, \ldots N &
\end{array}
$$

Where $N$ is the calculated number of time period, $P_{M}$ and $E_{M}$ are respectively the power and energy capacity of the storage system due to the installation site, grid power, etc., $S O C_{M}$ is the highest state of charge that allowed by the battery energy storage system, $S O C_{0}$ is the initial state of charge of the battery energy storage system. 


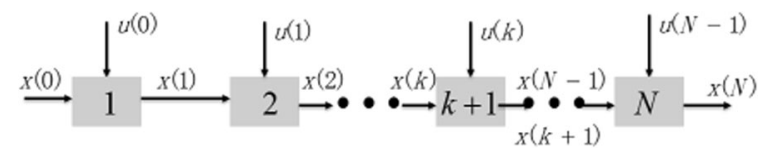

Fig. 1 Transition diagram of stage state

\subsection{The lower-level model}

Two-part electricity price is implemented for the gridconnected microgrid. The first part is the fixed demand capacity cost which is calculated according to the demand power. And the second part is the electricity cost bought from the connection line. For the microgrid operator, the fluctuation variance of the connection line means extral tarrif. As a result, the inner objective function is given as below:

$$
\min f=\sum_{i=1}^{N}\left\{P_{E S}(i)+P_{L}(i)-P_{G}(i)-\frac{\sum_{i=1}^{N}\left[P_{L}(i)-P_{G}(i)\right]}{N}\right\}^{2}
$$

The above equation shows the fluctuation variance of the power of the connection line within one day. $p_{E S}(i)$, $p_{L}(i)$, and $p_{G}(i)$ are respectively the energy storage power, load power and generation power in the microgrid system in the i time period.

The constraints are:

$$
\left\{\begin{array}{l}
-P_{E S} \leq p_{E S}(i) \leq P_{E S} \\
S O C_{m} \leq S O C(i) \leq S O C_{M} \\
-P_{G 0} \leq p_{E S}(i)+p_{L}(i)-p_{G}(i) \leq P_{L 0}
\end{array}\right.
$$

Where $P_{L 0}, P_{G 0}$ are respectively the maximum allowable consumption power and reverse power on the connect line. The first constrain is.

Here, $p_{E S}$ is maximum the charging and discharging power of the energy storage. Assuming that the energy storage system charging efficiency $\eta_{c}$ and discharge efficiency $\eta_{d}$ remains constant, set $\alpha$ as follows:

$$
\alpha=\left\{\begin{array}{l}
\eta_{c} \quad p_{E S}>0 \\
1 / \eta_{d} p_{E S} \leq 0
\end{array}\right.
$$

So we can get the equation:

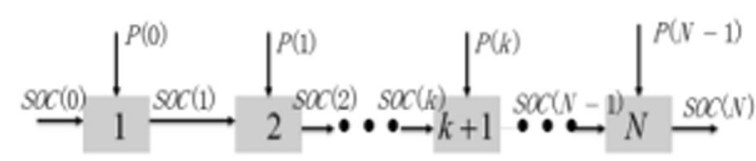

Fig. 2 Transition diagram of SOC's stage state

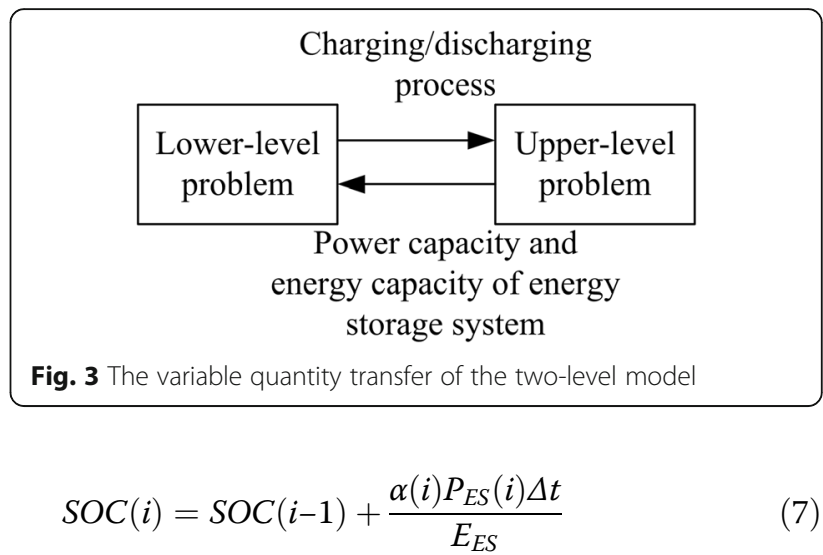

where $\Delta t$ is the calculating length of the time period.

\subsection{Solving algorithm}

It can be seen that the outer programming model is a quadratic problem and easy to solve. The inner programming mode is a mixed integer nonlinear programming (MINLP) problem, its objective function can be expressed as a form of univariate function and the dynamic programming method can be used to solve the problem. The dynamic programming method decomposes a multi-stage optimization problem into single-stage optimization problem by stage division, which is an effective algorithm to solve the problem. The dynamic programming model needs to determine the calculated decision quantity and state quantity. For each controllable resource, the power of each calculation period is the decision quantity in the dynamic programming model; for the energy storage, the SOC at the end of each calculation period is its state quantity, the initial state quantity and the end state quantity are known quantities.

The optimal strategy of the dynamic programming decision-making process has the property as follows: the rest of the decisions must be an optimal strategy when any of the state is taken as the initial level and initial state, regardless of the initial state and the initial decision. That is, if there is a N-level decision process with initial state of

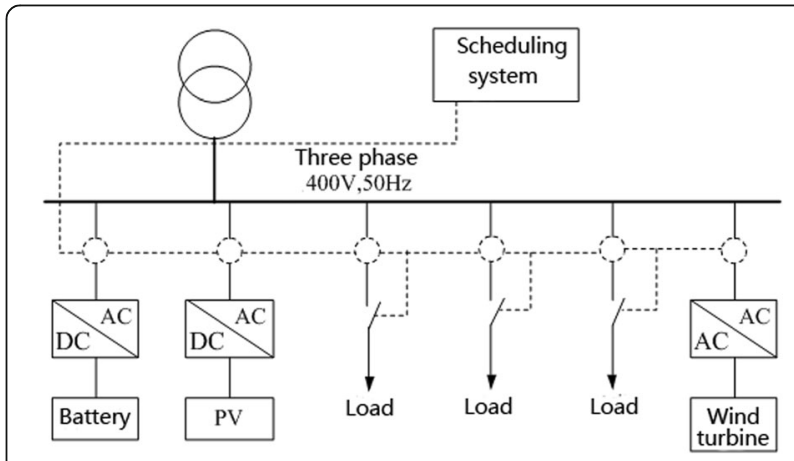

Fig. 4 System structure diagram of grid-connected microgrid 
Table 1 Energy storage configuration scenes

\begin{tabular}{lllll}
\hline Scene & $\begin{array}{l}\text { The maximum wind } \\
\text { power(kW) }\end{array}$ & $\begin{array}{l}\text { The } \\
\text { maximum } \\
\text { PV power } \\
(\mathrm{kW})\end{array}$ & $\begin{array}{l}\text { The } \\
\text { maximum } \\
\text { load } \\
(\mathrm{kW})\end{array}$ & probability \\
\hline S1 & 280 & 195 & 896 & $17 \%$ \\
S2 & 288 & 192 & 1132 & $21 \%$ \\
S3 & 414 & 205 & 1063 & $26 \%$ \\
S4 & 423 & 236 & 1031 & $19 \%$
\end{tabular}

$x(0)$, its optimal strategy is $\{u(0), u(1), \ldots u(N-1)\}$. Then, for a N-1-level decision process with initial state of $x(1)$, the decision set $\{u(1), u(2), \ldots u(N-1)\}$ must be the optimal strategy.

Figure 1 shows the state transfer diagram of the $\mathrm{N}$ level decision process. An N-level decision process can be expressed as follows:

$$
\begin{aligned}
& x(k+1)=f[x(k), u(k), k] \\
& x(0)=x_{0}
\end{aligned}
$$

The constraints in the above formula are: $x(k) \in X \in R^{n}$, $u(k) \in \Omega \subset R^{m}$. At this point, the programming problem can be described as solving an optimal control (decision) $\operatorname{series} u^{*}(k), k=0,1, \ldots N-1$, which can make the performance indicator minimum.

The solving method of dynamic programming problem can be divided into two directions: forward and backward. The forward direction means starting from the initial layer and calculating gradually to the end; the backward direction means starting from the end layer and reversing the solution. In practical problems, the backward direction is more commonly used. The paper adopt the backward direction method.

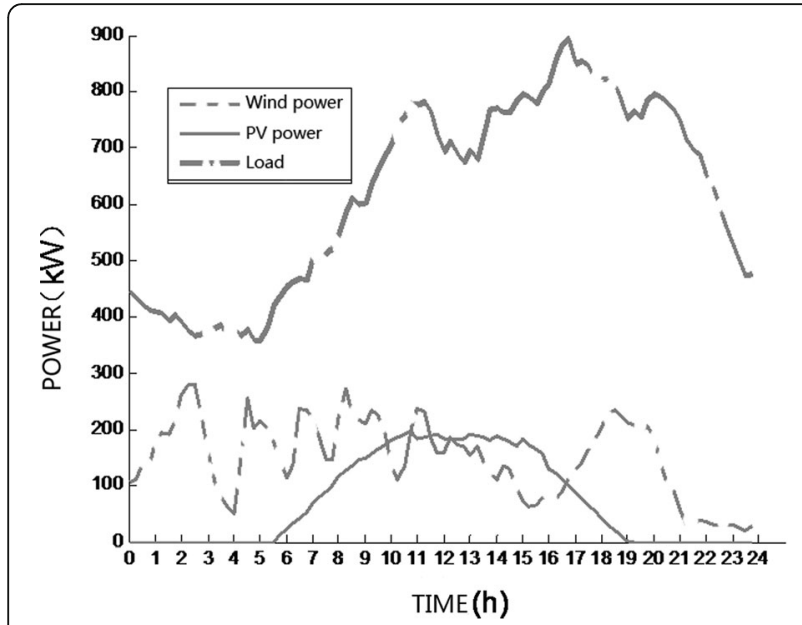

Fig. 5 Daily power generation and load curve of microgrid in scene S1

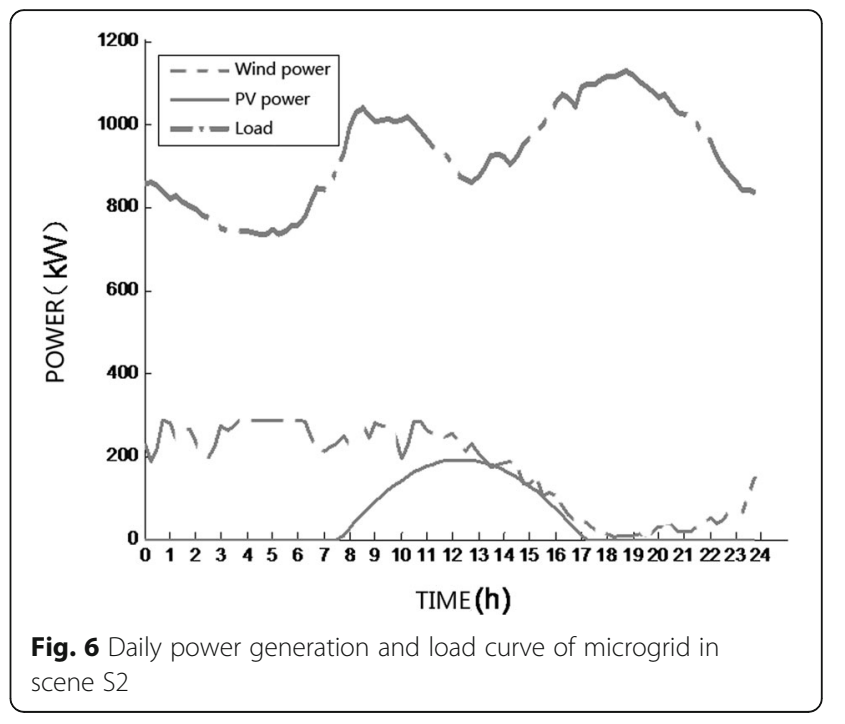

At each stage, SOC at the end is considered as the state quantity, the power of the energy storage $p_{E S}(i)$ is the decision quantity, the variance of the power becomes the corresponding cost function, and eq. (7) is the dynamic equation.

The power decision set of energy storage can be established through the charging and discharging power limit and the line power limit. The state set of energy storage can be established through the SOC range of operation. Enumeration method is adopted to solve the single stage MINLP problem. According to the second constrain in eq. (5), the state set is composed of discrete value from $S O C_{m}$ to $S O C_{M}$ by a step of $\triangle S O C$. The decision set can be calculated accordingly. The less $\triangle S O C$ value, the larger the decision set. As a result, it takes more time to calculate the optimal decision.

According to the steps above, the optimal charging and discharging process of energy storage system can be

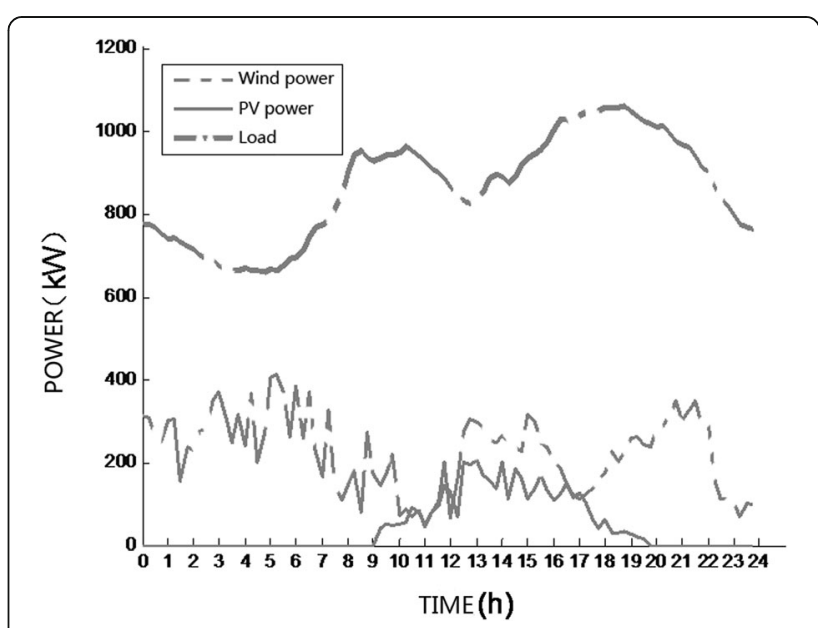

Fig. 7 Daily power generation and load curve of microgrid in scene S3 


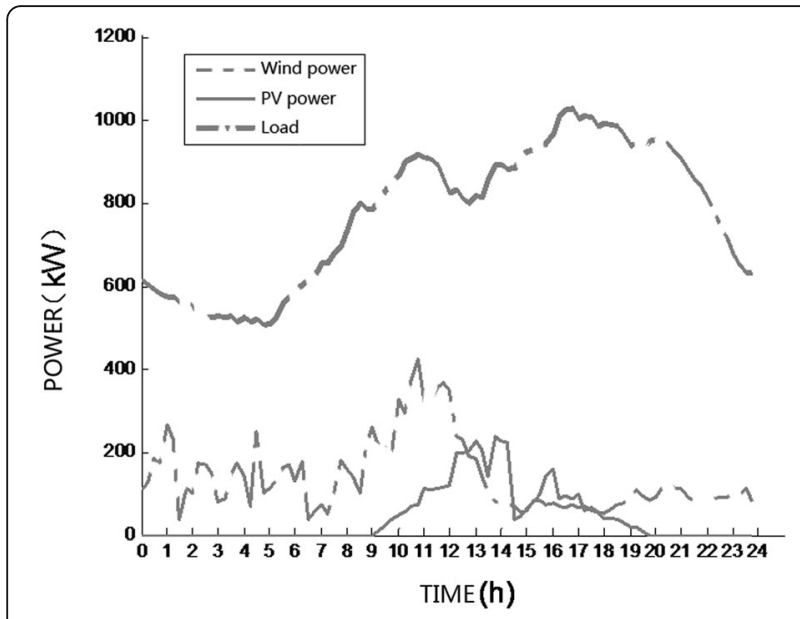

Fig. 8 Daily power generation and load curve of microgrid in scene 54

solved. Figure 2 shows the transition diagram of SOC's stage state.

From the inner problem we can get the optimal charging and discharging process of the energy storage system. The solve of inner problem is transferred to the upper-level model to get the optimal configuration of energy storage system. And the configuration is transferred to the lower-lever model as constrains. The iteration process is illustrated in Fig. 3.

\section{Case study}

In this case, a grid-connected microgrid with wind power, photovoltaic, battery energy storage and load is studied. The system structure of the microgrid is shown in Fig. 4.

In this system, the installed capacity of photovoltaic is $300 \mathrm{~kW}$, the installed capacity of wind power is $500 \mathrm{~kW}$, the maximum load is $1200 \mathrm{~kW}$, the maximum power limit of the connection line is $1000 \mathrm{~kW}$, and the reverse transmission power is limited to $500 \mathrm{~kW}$.

For the uncertainties of wind power, photovoltaic power and load, the multi-scene probability method is used to make the decision of the energy storage configuration. That is to say, the energy storage configuration is calculated in several scenes, and decisions are made according

Table 2 Optimize configuration results for energy storage in each SCENE

\begin{tabular}{llll}
\hline Scene & $\begin{array}{l}\text { The power of } \\
\text { energy storage } \\
\text { system(kW) }\end{array}$ & $\begin{array}{l}\text { The capacity of } \\
\text { energy storage } \\
\text { system(kWh) }\end{array}$ & $\begin{array}{l}\text { The cost of energy } \\
\text { storage system(k\$) }\end{array}$ \\
\hline S1 & 294.7 & 364.3 & 127.1 \\
S2 & 361.0 & 425.9 & 149.8 \\
S3 & 136.9 & 132.3 & 48.3 \\
S4 & 143.5 & 73.8 & 31.78 \\
\hline
\end{tabular}
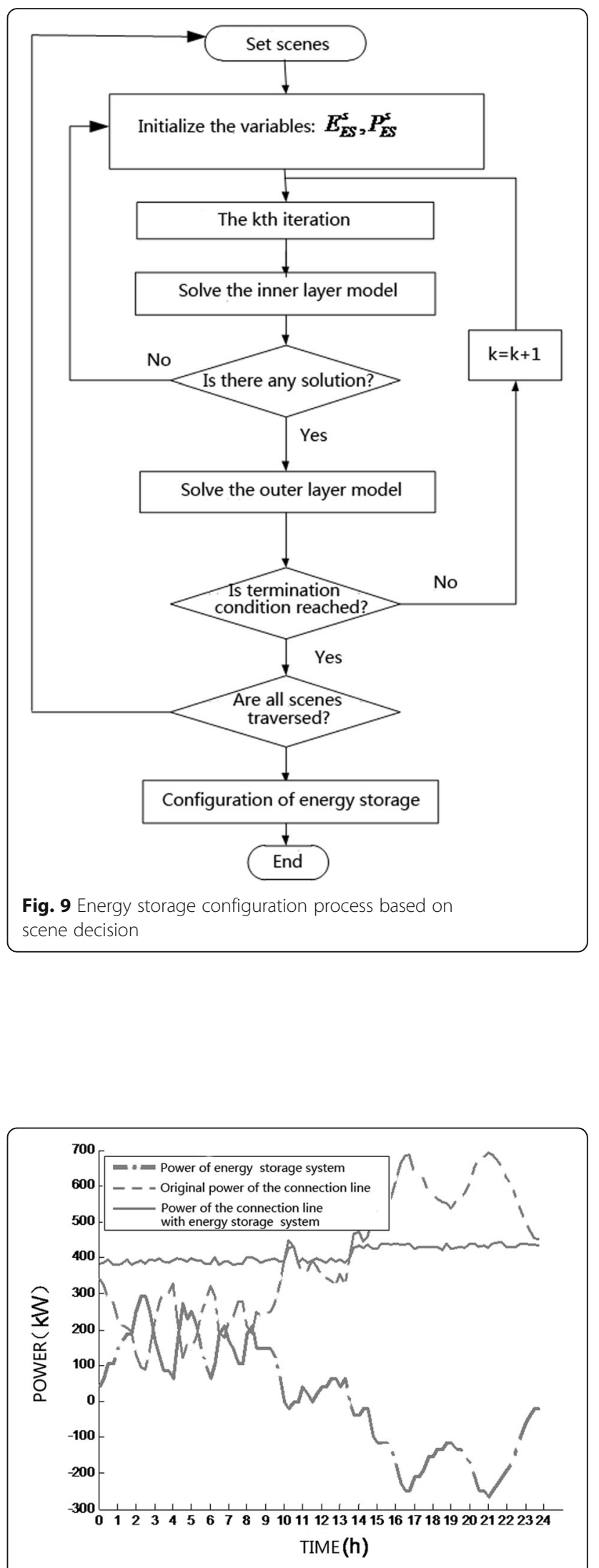

Fig. 10 Energy storage and contact line power curve in scene S1 


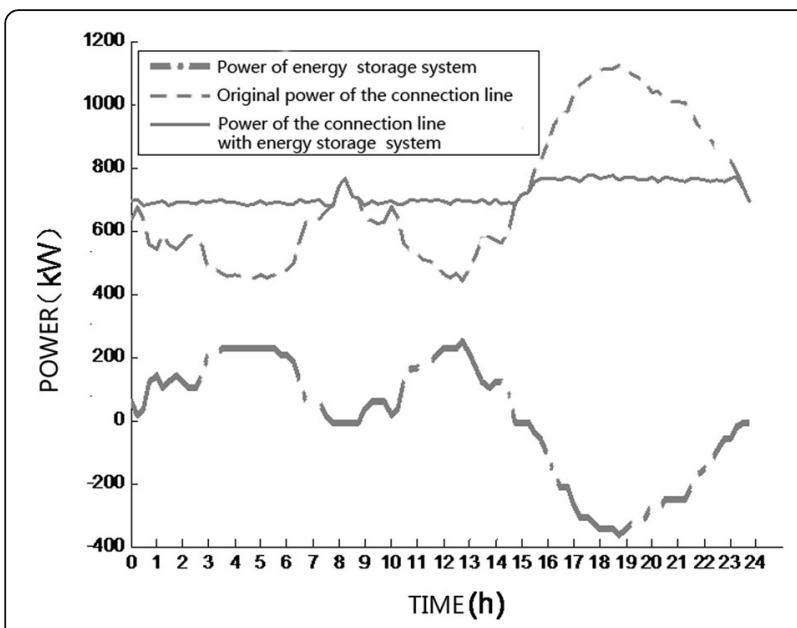

Fig. 11 Energy storage and contact line power curve in scene S2

to the probability level of each scene. Scene analysis is an effective method to solve stochastic problems. By modeling the possible scenes, the uncertainties in the model are transformed into multiple deterministic scene problems, where the difficulty of modeling and solving is reduced. The time series of a possible operating state in the period being studied is called a scene s, and the set of all possible scenes of the system is called the scene set $\mathrm{S}$. The uncertainty of the system can be simulated by generating a scene set.

Here, the historical data of wind power, photovoltaic power and load in this microgrid during one year is used for analysis, that is, the number of scenes is 365 . In order to trade-off between the computational burden and maintain a certain degree of credibility, an approximate subset of the original scene is selected using the probability distance to reduce the number of scenarios. The original scene set can be reduced to four scenes

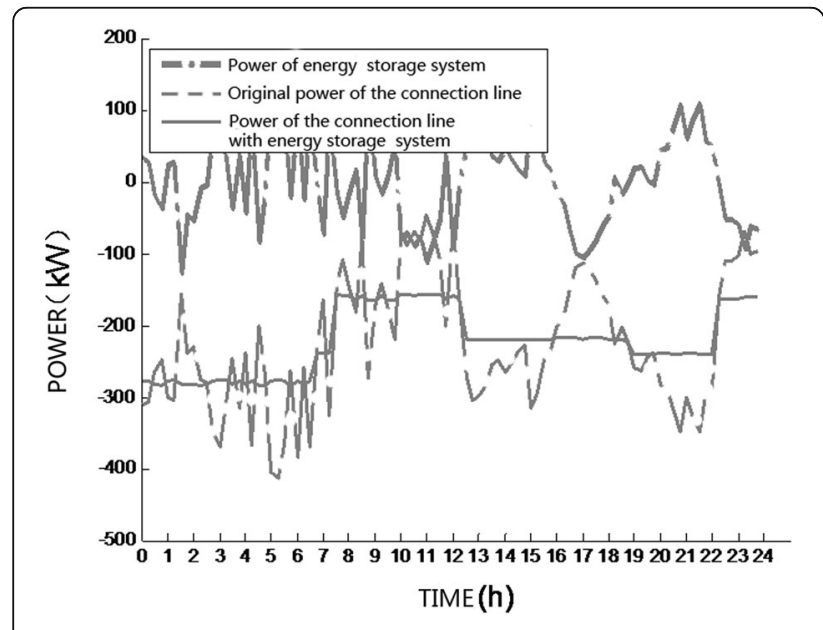

Fig. 12 Energy storage and contact line power curve in scene S3

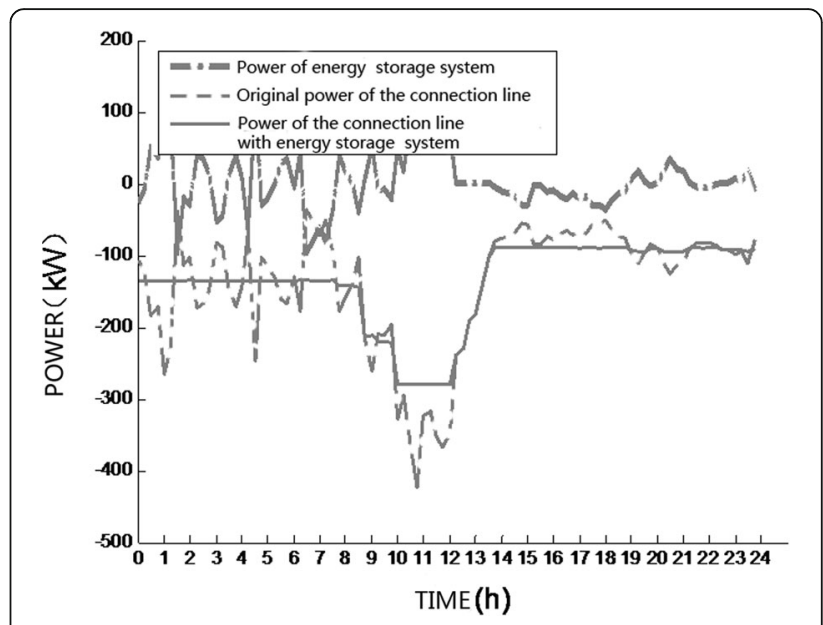

Fig. 13 Energy storage and contact line power curve in scene $\$ 4$

which are shown in Table 1 and Figs. 5, 6, 7 and 8. Table 2 shows the optimal configuration of energy storage in each scene. Figure 9 shows the energy storage configuration of grid-connected microgrid system based on scene decision.

The power curves of energy storage system and connection line in each scene are shown in Figs. 10, 11, 12 and 13. According to the configuration results of energy storage in each scene, the power and capacity of energy storage can be calculated as follows:

$$
P_{E S}=\frac{\sum_{s=1}^{n} P_{E S}^{s} p_{s}}{\sum_{s=1}^{n} p_{s}}, P_{E S}=\frac{\sum_{s=1}^{n} E_{E S}^{s} p_{s}}{\sum_{s=1}^{n} p_{s}}
$$

The energy storage configuration result is $227.4 \mathrm{~kW} /$ $240.7 \mathrm{kWh}$ after calculation. The values of the parameters are shown in Table 3. The value of $c_{1}$ and $c_{2}$ is given as an example for Lithium energy storage system cost nowadays. $\lambda$ is given considering the total cost of construction of distribution network and the reserve capacity of system.

After calculation, the standard deviation of the power fluctuation of connection line in the grid-connected microgrid can be suppressed within $50 \mathrm{~kW}$ (expected value) under this energy storage configuration.

Table 3 Optimal configuration of energy storage in each scenario

\begin{tabular}{lllll}
\hline Parameter & $\mathrm{C}_{1}$ & $\mathrm{C}_{2}$ & $\lambda$ & $\mathrm{SOC}_{\mathrm{m}}$ \\
& $\$ \cdot \mathrm{kW}-1$ & $\$ \cdot \mathrm{kWh}-1$ & $\$ \cdot k W-1$ & \\
\hline Value & 72 & 290 & 2180 & 0.2 \\
Parameter & $\mathrm{SOC}_{\mathrm{M}}$ & $\mathrm{P}_{\mathrm{LO}} \mathrm{kW}$ & $\mathrm{P}_{\mathrm{GO}} \mathrm{kW}$ & \\
Value & 1.0 & 800 & -500 & \\
\hline
\end{tabular}




\section{Summary}

This paper studies an optimal configuration strategy of energy storage in grid-connected microgrid and detail work is as follows:

(1) The two-layer decision model of energy storage capacity configuration is given. The decision variables of the upper-level model are the power and capacity of the energy storage and the objective is to minimize the initial investment and the fluctuation on the connection line. The decision variable of the lower-level programming model is the charging and discharging power of the energy storage, and the objective is the lowest power fluctuation of the connection line. The upper-level model is a quadratic programming problem, which is easy to solve. For the lower-level model which is not easy to be solved, the dynamic programming method can be used.

(2) A case study of a grid-connected microgrid containing wind power, photovoltaic, battery energy storage and load is given. The multi-scene probability method is used to make the decision on the configuration of energy storage according to the probability level of each scene. Finally, the result of the energy storage configuration is $227.4 \mathrm{~kW} / 240.7 \mathrm{kWh}$ under which the power fluctuation of connection line in the grid-connected microgrid can be suppressed within $50 \mathrm{~kW}$.

\section{Funding}

The National Key Research and Development Plan(2017YFB0903504); Science and Technology Project of the SGCC(5210EF17001c).

\section{Authors' contributions}

Jianlin Li proposed the main idea, Yushi Xue wrote this manuscript, Liting Tian and Xiaodong Yuan helped perform the study analysis with constructive discussions, professional advice and revised the manuscript. All authors read and approved the final manuscript.

\section{Competing interests}

The authors declare that they have no competing interests.

\section{Author details}

${ }^{1}$ State Key Laboratory of Operation and Control of Renewable Energy\&Storage Systems, China Electric Power Research Institute, Beijing 100192, China. ${ }^{2}$ SGCC Jiangsu Electric Power Research Institute, Nanjing 211103, China.

Received: 25 May 2017 Accepted: 19 September 2017

Published online: 02 October 2017

\section{References}

1. Li, X., Hui, D., \& Lai, X. (2013). Battery Energy Storage Station (BESS)-Based Smoothing Control of Photovoltaic (PV) and Wind Power Generation Fluctuations[J]. IEEE Transactions on Sustainable Energy, 4(2), 464-473.

2. Kawakami, N., Ota, S., Kon, H., et al. (2014). Development of a 500-kW Modular Multilevel Cascade Converter for Battery Energy Storage Systems[J]. Industry Applications IEEE Transactions on, 50(6), 3902-3910.

3. Huang, A. Q., Crow, M. L., Heydt, G. T., et al. (2010). The Future Renewable Electric Energy Delivery and Management (FREEDM) System: The Energy Internet[J]. Proc IEEE, 99(1), 133-148.

4. Wang, G., Ciobotaru, M., \& Agelidis, V. G. (2015). Optimal capacity design for hybrid energy storage system supporting dispatch of large-scale photovoltaic power plant[J]. Journal of Energy Storage, 3, 25-35.
5. Ogimi, K., Yoza, A., Yona, A., et al. (2012). A study on optimum capacity of battery energy storage system for wind farm operation with wind power forecast data[C]// IEEE, International Conference on Harmonics and Quality of Power. IEEE, 118-123.

6. Kargarian, A., \& Hug, G. (2016). Optimal sizing of energy storage systems: a combination of hourly and intra-hour time perspectives[J]. IET Generation Transmission \& Distribution, 10(3), 594-600.

7. Asao, T., Takahashi, R., Murata, T., et al. (2008). Evaluation method of power rating and energy capacity of Superconducting Magnetic Energy Storage system for output smoothing control of wind farm[C]// International Conference on Electrical Machines. IEEE, 1-6.

8. Liang L, Li J, Dong $\mathrm{H}$. An optimal energy storage capacity calculation method for $100 \mathrm{MW}$ wind farm[C]// International Conference on Power System Technology. 2010:1-4.

9. Jia, H., Fu, Y., Zhang, Y., et al. (2010). Design of Hybrid Energy Storage Control System for Wind Farms Based on Flow Battery and Electric DoubleLayer Capacitor[C]// Power and Energy Engineering Conference. IEEE, 1-6.

10. Makarov, Y. V., Du, P., Kintner-Meyer, M. C. W., et al. (2012). Sizing Energy Storage to Accommodate High Penetration of Variable Energy Resources[J]. IEEE Transactions on Sustainable Energy, 3(1), 34-40.

11. Jian, X., Nian, L., Lei, Y., et al. (2016). Optimal allocation of energy storage system of PV microgrid for industries considering important load[J]. Power System Protection and Control, 09, 29-37.

12. Kornelakis, A., \& Koutroulis, E. (2009). Methodology fo $r$ the design optimisation and the economic analysis of grid-connected photovoltaic systems[J]. IET Renewable Power Generation, 3(4), 476-492.

13. Tan, X., Wang, H., \& Li, Z. (2014). Multi-objective Optimization of Hybrid Energy Storage and Assessment Indices in Microgrid[J]. Automation of Electric Power Systems, 08, 7-14.

14. Jemaa, A. B., Essounbouli, N., \& Hamzaoui, A. (2014). Optimum sizing of hybrid PV/Wind/battery installation using a fuzzy PSO[C]// International Symposium on Environmental Friendly Energies and Applications. IEEE, 1-6.

15. Xie, S., Yang, L., \& Lina, L. (2012). A Chance Constrained Programming Based Optimal Configuration Method of Hybrid Energy Storage System[J]. Power System Technology, 05, 79-84.

16. Bludszuweit, H., \& Dominguez-Navarro, J. A. (2011). A Probabilistic Method for Energy Storage Sizing Based on Wind Power Forecast Uncertainty[J]. IEEE Trans Power Syst, 26(3), 1651-1658.

17. Yuan, Y., Li, Q., \& Wang, W. (2009). Optimal operation strategy of energy storage applied in wind power integration based on chance-constrained programming[C]// International Conference on Sustainable Power Generation and Supply, 2009. Supergen IEEE, 1-6.

\section{Submit your manuscript to a SpringerOpen ${ }^{\circ}$ journal and benefit from:}

- Convenient online submission

Rigorous peer review

- Open access: articles freely available online

- High visibility within the field

- Retaining the copyright to your article

Submit your next manuscript at $>$ springeropen.com 